\title{
LA DATACIÓN Y PROCEDENCIA DE LAS GLOSAS EMILIANENSES Y SILENSES: ANOTACIONES CRÍTICAS A LOS NUEVOS PLANTEAMIENTOS
}

\author{
Claudio Garcia Turza* y Javier García Turza**
}

\begin{abstract}
RESUMEN: En el presente artículo se pretende colaborar en el estudio bistórico y filológico de las Glosas Emilianenses y Silenses, tan necesitadas de investigaciones minuciosas desde las más variadas perspectivas. En concreto, los autores, a partir del análisis crítico de algunas de las aportaciones más recientes y prestigiosas, alertan sobre la insuficiente consistencia de los argumentos aducidos tanto para retrasar la datación de las Glosas como para asignarles el lugar de procedencia. Basan sus reservas científicas en razones principalmente paleográficas y lingüísticas.

RÉSUMÉE: Dans cet article on prétend collaborer à l'étude bistorique et philologique des Gloses Emilianenses et Silenses, dont des recherches minutieuses à partir des perspectives les plus variées seraient d'une grande nécessité. En somme, en partant de l'analyse critique de quelques apports les plus récents et prestigieux, les auteurs donnent l'alerte sur la consistance insuffisante des arguments allégués autant pour retarder la date des Gloses que pour assigner leur lieu d'origine. Ils fondent leurs réserves scientifiques sur des raisons essentiellement paléographiques et linguistiques.
\end{abstract}

Como es bien sabido, las glosas vienen interpretándose como una serie de anotaciones en latín, romance y vasco, interlineadas o marginales, escritas en

* Catedrático de Filología Española de la Universidad de La Rioja.

**: Profesor Titular de Historia Medieval de la Universidad de La Rioja. 
códices latinos medievales, con las que se pretende fundamentalmente resolver dificultades de comprensión del sentido de esos textos latinos.

Todo el mundo sabe, asimismo, que las glosas de mayor entidad filológica y cultural son las denominadas "Emilianenses" " "Silenses". El códice AEmilianensis 60 , en que figuran las primeras, se encuentra depositado en la Biblioteca de la Real Academia de la Historia de Madrid; por su parte, las segundas fueron escritas sobre el códice add. 30853 de la British Library de Londres.

Los investigadores de estas obras echábamos en falta desde hace tiempo un estudio comparativo de ambos textos. Pues bien, los profesores José Manuel Ruiz Asencio y César Hernández Alonso han efectuado recientemente, en cierta medida, dicho análisis contrastivo, deteniéndose el primero en un enfoque paleográfico y el segundo en un punto de vista básicamente lingüístico; además, la publicación, que llevó a cabo el Excelentísimo Ayuntamiento de Burgos ${ }^{1}$, incluye, junto a la edición crítica y facsímil de las glosas, un preámbulo del Profesor Manuel Alvar ${ }^{2}$, un estudio histórico a cargo de Don Gonzalo Martínez Díez ${ }^{3}$ y otro literario del Profesor Fradejas Lebrero ${ }^{4}$.

Entre las novedades que, a juicio de los mencionados investigadores, Ruiz Asencio y Hernández Alonso, se desprenden de su estudio, destacan las siguientes: a) el descubrimiento de que no existen dos glosadores, uno en San Millán y otro en Silos, sino que "nos encontramos probablemente ante una única persona, que nos ha dejado como testimonio de su labor como glosador un original de su mano (el Emilianense) y una copia (el Silense) de otro libro suyo perdido" (pág. 83); b) el origen vasco de ese glosador; c) el carácter "castellano-riojano" de la lengua de las glosas tanto Emilianenses como Silenses; d) el monasterio en que trabaja, que quizá no sea San Millán de la Cogolla; e) la datación de las glosas emilianenses, que han de situarse con seguridad en el último cuarto del siglo XI; $\mathrm{Y}$ f) el lugar donde se hizo la copia de Silos, que probablemente sea San Millán.

La repercusión científica de estas investigaciones, a nuestro juicio no siempre certeras, unida a unas interpretaciones que vienen suscitando confusión en diferentes ámbitos sociales, particularmente castellanos y riojanos, nos ha forzado a efectuar un análisis detenido de las colaboraciones de los dos autores citados. En esta ocasión, avanzamos en primer lugar una síntesis rigurosa de las ideas centrales de dichas colaboraciones y en segundo lugar el juicio crítico que éstas nos merecen.

1. HERNÁNDEZ ALONSO, C., et alii, Las Glosas Emilianenses y Silenses. Edición crítica y facsímil. Burgos, 1993. Para el estudio de J. M. RUIZ ASENCIO, Hacia una nueva visión de las Glosas Emilianenses y Silenses, cfr. las págs. 83-118; la aportación de C. HERNÁNDEZ ALONSO, Las Glosas. Interpretación y estudio lingüístico, figura en las págs. 63-82, y sus Notas a las Glosas Emilianenses y Silenses, en las págs. 255-290.

2. Ibíd.: 9-16.

3. El condado de Castilla y los monasterios de Santo Domingo de Silos y San Millán de la Cogolla: 17-39.

4. Literatura en el siglo $X I$ : 41-62. 
La síntesis que hacemos se vertebra en torno a las cuestiones de autoría, lugar de redacción, cronología, lengua y propósito, tanto de los textos latinos como de las glosas correspondientes.

\section{El Códice EMilianense}

Sólo hubo un autor en la elaboración del texto latino Amilianensis 60 . Se llamaba Munio, según se constata en diferentes partes del códices. El estudio comparativo realizado por Ruiz Asencio, que se orienta fundamentalmente a confrontar las grafias y abreviaturas que se emplean en las distintas partes del manuscrito, permite llegar a esa conclusión. Sin embargo, como advierte este mismo investigador, se observan, por un lado, diversas técnicas en la preparación de los folios para recibir el texto; por otro, aparecen tres módulos distintos de escritura; y, por último, se aprecia diversidad temática entre las tres partes del códice. El conjunto de estos rasgos aboga en favor de la idea de encontrarnos ante un códice facticio, formado ya en la Alta Edad Media por la unión de piezas originariamente distintas, aunque escritas por la misma mano.

Por otra parte, en relación con las glosas, Ruiz Asencio concluye, a partir de un minucioso análisis gráfico, que fueron realizadas asimismo por una sola mano, aunque en diferentes momentos. Frente a esta tesis, habrá que recordar que el profesor Díaz y Díaz, basándose en la variedad de trazos y en las distintas calidades de la tinta, sostiene la presencia de al menos dos glosadores ${ }^{6}$.

Pocos datos se ofrecen en esta colaboración en torno al monasterio en el que se copió el texto latino del códice Emilianense. Tan solo se expone la hipótesis de que el primer centro poseedor del manuscrito ha de ser buscado en zona de habla vasca, pero en territorio del reino de Castilla. Nótese, sin embargo, que Díaz y Díaz se inclina a pensar que el manuscrito 60 es originario de región navarra o pirenaica, en el sentido medieval de ambos términos, esto es, una región que podría ir desde el valle del Mena hasta el Este de Navarra ${ }^{7}$. De lo que no cabe duda, según este último autor, es que el manuscrito se encontraba ya en el siglo X o en San Millán o más probablemente en sus alrededores ${ }^{8}$.

Respecto del lugar donde se escriben las glosas, según Ruiz Asencio, no puede asumirse la idea de que se hayan manuscrito en el cenobio emilianense: se hace muy cuesta arriba admitir como algo corriente, afirma este autor, que en un monasterio del prestigio y de la riqueza de San Millán, bien organizado y con abundante clerecía, se permitiera que algunos monjes, maestros o discípulos, des-

5. Hec est uia et opus monaci./Munnioni presbiter librum (fol. 28r); Munnionem indignum memorare pusillum (fol. $48 \mathrm{v}$ ).

6. DÍAZ Y DÍAZ, 1978: 27-29.

7. Ibid:: 26 y 27.

8. Ibíd: 27. 
trozaran los libros introduciendo en ellos anotaciones para ejercicios escolares y glosas en lengua vulgar. Lo lógico es, insiste Ruiz Asencio, que para estas tareas se recurriera al empleo de tablillas de cera, tan útiles y baratas para estos fines.

A su juicio, la incorporación de dos glosas en vascuence "inevitablemente nos ha de llevar al solar de Euskalerría, tal como era en la Edad Media, la búsqueda de la patria del glosador" (pág. 94). "Más difícil es determinar en qué zona del País Vasco (...) puede estar la patria chica de nuestro hombre. Por razones de tipo geográfico e histórico parece que debemos inclinarnos hacia Álava, donde tantos intereses tuvo el monasterio de San Millán, como todas las otras instituciones eclesiásticas importantes asentadas en la zona sur de La Rioja. Tal vez incluso pueda proceder del riojano Valle de Ojacastro, antaño perteneciente a Castilla y hoy en La Rioja, donde, como es bien sabido, el vascuence estuvo en uso hasta la baja Edad Media" (pág. 107).

Refuerza esta postura la hipótesis, defendida con insistencia por Ruiz Asencio, de que el Emilianense 60 proceda de algunas de las incorporaciones a San Millán de iglesias pertenecientes a la zona alta de la propia Rioja y a las provincias vascas de Vizcaya y Álava. De una de estas, quizás tras la incorporación de La Rioja a Castilla, ingresaría en San Millán un lote cuantioso de libros no lujosos, útiles para la liturgia, para la práctica de la confesión y para la lectura piadosa, que era obligatoria en toda comunidad benedictina.

En cuanto a la datación del Emilianense 60, Ruiz Asencio es de la opinión de que debió de escribirse en la segunda mitad del siglo XI, e incluso sugiere como más probable el último cuarto de ese siglo. Basa sus apreciaciones en la comprobación de la existencia de tres escuetos elementos gráficos de origen típicamente carolino; a saber: a) ausencia casi absoluta de la distinción $t j$ con sonido "silbante" y $t i$ con sonido "fuerte"; b) presencia de un testimonio de sufijo - us con forma abreviada de 9 cursivo; y c) existencia de un Crismón de formas gráficas propias de la segunda mitad del siglo XI. No obstante, reconoce que tanto las formas alfabéticas como los signos abreviativos que presenta el manuscrito se corresponden con los rasgos que caracterizan a los códices visigóticos de la segunda época: fines del siglo IX-primera mitad del siglo $\mathrm{X}^{10}$. A este respecto, es bien conocido que Díaz y Díaz sitúa en los alrededores del 900 la copia del Emilianense $60^{11}$.

9. "Lo que ocurre en este caso [presencia de la grafia $t j$ ] es que se trata de uno solo entre un centenar en los que la solución es siempre ti. Podríamos preguntarnos si se le fue materialmente la mano al escriba en esta palabra y por ello no debemos tenerlo en cuenta, o por el contrario, si fue el copista tan respetuoso con el ejemplar que le servía de modelo que copió todos los $t i$ tal como allí estaban escritos salvo en una ocasión en que puso un $t j$, con la forma que era conocida en su tiempo" (pág. 92).

10. "En efecto, en esta mano de Munio se cumplen los rasgos que caracterizan a los códices visigóticos de la segunda época, como son: letras más altas que anchas, los astiles tienen forma de maza, las terminaciones finales de $m, n, b, i$ tuercen ligeramente hacia afuera, o a veces, las menos, quedan verticales, y finalmente las terminaciones de - $u s$ y -ue se producen mediante $s$ volada" (pág. 91).

11. Cfr. DÍAZ Y DÍAZ, 1978:27. El mismo autor, 1991: 237, sitúa la copia del texto mencionado en el siglo IX. 
Por lo que respecta a la fecha en que se escriben las glosas, hay indicios más que suficientes, según Ruiz Asencio, para situarlas en el tercer período de la escritura visigótica, que se extiende desde la segunda mitad del siglo $\mathrm{X}$ hasta fines del XI. En efecto, son rasgos gráficos propios de ese período la distinción sistemática de $t i$ y $t j$, el trazado de líneas inclinadas en los remates de los astiles, la desviación hacia la derecha de las patas de $b, m$ y $n$ y la presencia de semícolon con forma de $s$ volada (pág. 96).

Ahora bien, Ruiz Asencio todavía precisa más la datación al situar la escritura del glosador "a partir de 1070-1075" (pág. 107), si bien ésta no debe sobrepasar los límites del XI. En su opinión existen dos argumentos fundamentales sobre los que puede apoyarse su propuesta. En primer lugar, se detecta en las glosas la presencia de lo que "se ha destacado en repetidas ocasiones" como "seguros influjos carolingios en la mano del glosador", el cual utiliza, en orden a las abreviaturas, soluciones que no son las típicas de la escritura visigótica, sino de la carolina: empleo de la $I$ alta con travesaño para abreviar $i n$; de $d$ y $k$ con la línea cruzando el astil para abreviar de y $k e$; de $p$ con línea que corta el caído para la abreviatura de per $\mathrm{y}$, finalmente, la abreviatura de la disyuntiva $u e l$ mediante $l$ cruzada por línea (que, por cierto, se documenta tan solo dos veces y que, a su juicio, no pudo copiarse de un glosario latino-romance porque éstos -insiste- no existían en aquel tiempo) en vez del clásico visigótico consistente en una $u$ y una $l$ con línea de abreviación. Sin embargo, Ruiz Asencio afirma que de todos los elementos precedentes "sólo el último -la abreviación de uel- denota verdadero influjo carolingio; los demás son soluciones gráficas que encontramos en documentos y en algunos códices visigóticos anteriores a la existencia del influjo ultrapirenaico en los reinos peninsulares" (pág. 99).

El empleo de estos usos franceses sobre la escritura visigótica en nuestras glosas habrá de ser coetáneo -según Ruiz Asencio- a la presencia de rasgos carolinos en documentos pertenecientes a los reinos de Castilla-León y Aragón, y que se fechan a partir de 1061 .

El segundo argumento estriba en el hecho de que la mano del glosador se inserta en el estilo de escritura que nos trasmite un documento real navarro de 22 de abril de $1073^{12}$.

Nótese al final de este punto que Díaz y Díaz, por su parte, operando también con argumentación paleográfica, ya retrasó, con la debida cautela, la fecha de escritura de las glosas a los primeros decenios del siglo $\mathrm{XI}^{13}$.

12. Catedral de Pamplona, sign. K25. Se trata de una carta del monarca Sancho de Peñalén, en la que dona ciertas heredades a doña Sancha, su aya, y al marido de ésta, el señor Sancho Fortuniones.

13. "Se hace imprescindible abordar el problema de la posible data de estas glosas. Es bien sabido que no han sido estudiadas con la debida profundidad desde el punto de vista paleográfico [...] Se recibe la sensación, en tanto aguardamos un estudio tipológico atento de todas las notas y glosas, de que la fecha que actualmente se atribuye a éstas se ha adelantado demasiado, quizá varios decenios [...]. Contamos sólo, en firme, con el texto continuo de la doxología oracional que aparece en el 
En lo referente a la importante cuestión de la lengua de las Glosas Emilianenses, las aportaciones del profesor Hernández Alonso serán analizadas posteriormente con detalle en nuestro estudio sobre las Silenses. De momento, baste señalar que, para este autor, las Glosas romances, tanto Emilianenses como Silenses, están escritas en un castellano-riojano popular con tendencias cultas, "con una docena aproximadamente de rasgos específicos de la Rioja" (pág. 64), "y de ninguna manera en navarro-aragonés" (pág. 75). Este lingüista llama a la lengua de las glosas romances castellano-riojano, porque "sabiendo que hay [en ellas] un buen número de rasgos específicos de la Rioja, son muchos más los fenómenos comunes a ambas comunidades de habla que los diferenciadores" y porque, añade, "el riojano a partir del siglo $\mathrm{X}$ fue aproximándose gradualmente al castellano" (pág. ibíd.).

Entrando en el propósito por el que Muño copió el Emilianense 60, Ruiz Asencio, al constatar que el contenido de este códice -relatos de vidas de santos, pasión y misa de Cosme y Damián y sermones de Cesáreo de Arlés- encaja a la perfección con el del Silense -homiliario y penitencial-, concluye que ambos códices "responden a las necesidades litúrgicas, de predicación y práctica de la confesión propias de una institución eclesiástica” (pág. 117).

Más controvertida resulta la interpretación de los diferentes móviles que impulsaron al glosador a escribir las glosas. En el trabajo de Ruiz Asencio se comprueban las siguientes finalidades: la primera y menos divulgada, introducir correcciones al texto latino, lo que, a su juicio, no precisa de la existencia de un libro que sirva de modelo. La segunda, fundamental, se relaciona con la enseñanza o aprendizaje del latín; en este sentido, Hernández Alonso considera que las Emilianenses son la primera muestra espléndida de un método de enseñar latín. La tercera consiste en aclarar el texto mediante la inclusión de sinónimos latinos, expresiones romances o vascas.

A este respecto, sugiere Ruiz Asencio que el glosador, aunque fuera maestro de latín, manifiesta una notable ignorancia por no haber respetado el venerable manuscrito que la comunidad puso en su mano para llenarlo de glosas en romance, y por sus conocimientos, muchas veces deficientes, de la lengua que pretendía enseñar. No obstante esta impericia, común en el momento inmediatamente anterior a la implantación de las innovaciones cluniacenses, Ruiz Asencio le reconoce dos méritos indudables: "su inteligencia, bien reflejada en la variedad de matices que se observan en sus glosas romances, y su osadía, que le lleva a inten-

margen exterior del folio 72 ; y este texto nos lleva, por el modo de trazar la $t j$, por la forma de -et, por los remates de algunos astiles, por el uso extraño de alguna $I$ longa y por el diseño de la $x$, al siglo XI bastante entrado" (DÍAZ Y DÍAZ, 1978: 29-30). Conscientes de esa necesidad de analizar con mayor detalle esta cuestión, los autores del presente trabajo venimos realizando desde hace tiempo un estudio histórico-filológico sobre las glosas y los glosarios hispánicos de los siglos X y XI, cuyos resultados comenzarán pronto a ver la luz. 
tar reflejar con un alfabeto antiguo e imperfecto los sonidos que emiten los hombres de su tiempo para comunicarse entre ellos" (pág. 108).

Hernández Alonso enfatiza aún más esta última cualidad del glosador: "extraordinaria agilidad, imaginación y osadía suponía el escribir el romance con la grafía de una lengua madre, sin que estuviera codificado el método ortográfico ni existiera una tradición" (pág. 73).

\section{El CÓDICE SILENSE}

Para Ruiz Asencio, todo el manuscrito, tanto el cuerpo del códice como las glosas, fue copiado por una misma mano. Estamos pues, "sin lugar a dudas" (pág. 113), ante un único copista, idea compartida unánimemente por los paleógrafos. Es más, para ese investigador, el manuscrito fue revisado inmediatamente después de la copia por el mismo escriba mediante el cotejo del texto con el ejemplar que le sirvió de modelo. No de otra forma pueden explicarse las adiciones textuales muy largas, de más de una línea.

Mayor interés tiene, según Ruiz Asencio,"el descubrimiento de que no existen dos glosadores, uno en San Millán y otro en Silos, sino que nos encontramos probablemente ante una única persona, que nos ha dejado como testimonio de su labor como glosador un original de su mano (el Emilianense) y una copia (el Silense) de otro libro suyo perdido" (pág. 83). En efecto, el sistema abreviativo utilizado en las glosas Silenses es semejante al que tienen las Emilianenses. Además, en ambos repertorios de glosas aparece uel en abreviatura carolina y los signos de remisión de texto a glosa, aunque con una mayor variedad, son prácticamente los mismos que aparecen en el Emilianense. Añádase a estos argumentos la presencia en ambas glosas de idénticas técnicas glosadoras, sumamente elaboradas.

Interesa señalar en este punto que Hernández Alonso sostiene, por el contrario, que existieron dos glosadores, apoyándose en la creencia de que el monje que escribió las Silenses "era un hombre culto, más que el de las Emilianenses, seguramente uno de los más cultos de su Comunidad, con visión original y con valentía" (pág. 65).

Siguiendo el hilo argumentador de Ruiz Asencio, para establecer el lugar donde se realizó la copia del Silense tendríamos que recomponer las siguientes circunstancias. En primer lugar, el monasterio de San Millán de la Cogolla recibiría el Amilianensis 60 tal como hoy lo conocemos y el original o modelo (texto y glosas) de las Silenses. Después, ante la necesidad de dotar al renovado monasterio de Silos de un fondo bibliográfico idóneo, se solicitaría al cenobio de San Millán, entre otras obras, una copia del manuscrito, hoy perdido, que sirvió de modelo al Silense (códice add. 30853 de la British Library de Londres). 
Finalmente, el lugar exacto en que se escribió el texto requerido bien pudo ser el monasterio de San Millán, pero sin descartar el monasterio silense ${ }^{14}$.

Sobre la fecha en que se copió el códice Silense, Ruiz Asencio estima que el análisis paleográfico permite situar nuestro ejemplar en el cuarto período de la escritura visigótica, es decir, el que corre por los años finales del siglo XI y principios del XII. Distintas, sin embargo, han sido las apreciaciones de otros eminentes especialistas: García Villada, Gómez Moreno, Millares Carlo y Menéndez Pidal se inclinan por el siglo $\mathrm{X}$, mientras que Férotin y Díaz Díaz, entre otros, lo llevan a mediados del $\mathrm{XI}^{15}$.

A su vez, Hernández Alonso, a partir de argumentos fonéticos (inexistencia del diptongo decreciente $e i^{16}$, monoptongación constante $a u>O^{17}$ y cambio de timbre de vocal postónica conservada ${ }^{18}$ ), concluye que la escritura de las glosas del Silense -así como del Emilianense- no puede ser anterior a la segunda mitad del siglo XI.

Como antes se dijo, en opinión de Hernández Alonso, la lengua de las glosas romances, Emilianenses y Silenses, es el dialecto castellano-riojano. Todavía más, según indica Ruiz Asencio, la coincidencia más importante entre ambos códices es que las glosas romances que contienen "corresponden al mismo dialecto, como es reconocido de forma unánime por cuantos filólogos se han acercado al tema. Es evidente que se observan algunas pequeñas diferencias entre Emilianenses y Silenses, pero se han de considerar como dubitaciones de una len-

14. "Argumentos existen a favor de ambos, porque era normal en aquel entonces que se prestasen los libros a un monasterio hermano para ser copiados, y también que se recibiese el encargo de hacer una copia en el propio monasterio donde se hallaba custodiado. Gómez-Moreno, según nos dice Menéndez Pidal [?], consideraba la escritura del códice bien diferente de la que se empleaba en otros manuscritos de Silos, mientras que las miniaturas y dibujos de iniciales, tema en el que era un experto, le recordaban las técnicas seguidas en San Millán de la Cogolla. Díaz y Díaz por su parte lo considera un producto del scriptorium silense. Para resolver la duda, sería necesario tener delante la comparación de los manuscritos de ambos monasterios" (pág. 118).

15. Para esta cuestión, cfr. DÍAZ Y DÍAZ, 1978: 32 y n. 59.

16. "En las Glosas, tanto Emilianenses como Silenses, sólo aparece la forma -ero (omiciero, terzero, ...), excepto en un cultismo aislado. Esto nos dice que esa es la pronunciación general. Y si $R$. Menéndez Pidal señala, haciendo porcentajes sobre el material que estudió, que en la primera mitad del siglo XI se documentan las formas -eiro y -ero, mientras que en la segunda mitad de ese siglo el 98\% de los casos ya muestran -ero; debemos admitir que las Glosas pertenecen a esta época. De ningún modo podemos retrotraerlas al s. $\mathrm{X}$, en que un $35 \%$ de los casos estudiados utilizan -airo, -eiro; $y$ un 65\% -ero. Es sólo un indicio, pero muy llamativo, de que las Glosas pertenecen al siglo XI y muy probablemente a la segunda mitad" (pág. 76).

17. "En las glosas tenemos sota y sotare ( $\angle$ SALTARE) dos veces, que muestran una evolución tardía, pues la forma soto y otba, según Menéndez Pidal, no aparece casi hasta el s. XII [...]. He aquí un indicio más de que las Glosas no pueden ser anteriores a la segunda mitad del XI" (pág. 77).

18. "En algún caso, la postónica se cambia por otra (p. ej. cuempetet), fenómeno que R. MENÉNDEZ PIDAL, 1986: 512) sitúa entre 1067 y 1100. Este es otro dato que apoya nuestra creencia de que las Glosas pertenecen a la segunda mitad del XI, y son anteriores al 1080" (pág. 78). 
gua en nacimiento desde el momento que esas diferencias ocurren también con las glosas que se extraen de un solo códice, ya sea el de Silos o el de San Millán" (pág. 117).

En términos análogos se expresa Hernández Alonso, para quien, entre las glosas Silenses y las Emilianenses no se perciben "notables diferencias lingüísticas, sino un mismo estado de lengua, con ligeras divergencias ortográficas, y, tal vez, -no puede pasar de meras hipótesis- algunas fonéticas" (pág. 82). Dicho con otras palabras, Hernández Alonso defiende contundentemente que "por la lengua que utilizan [las glosas] y las peculiaridades riojanas del texto, creemos que [el autor] era de la Rioja, que pudo anotar el texto en un castellano-riojano, y con una clara marca cultista" (pág. 65).

En relación con la naturaleza del sistema lingüístico propio de las glosas Emilianenses y Silenses, Hernández Alonso se pregunta por qué tuvieron que componerse conscientemente en una lengua romance y, más concretamente, en dialecto castellano-riojano. A la primera cuestión contesta este investigador aportando la hipótesis de que se produjera una reacción de valores culturales autóctonos contra el poderoso movimiento cluniacense, que pretendía, entre otros grandes propósitos, potenciar el estudio del latín en los monasterios. A la segunda pregunta, responde Hernández Alonso que, al haberse producido la ocupación de La Rioja por Alfonso VI en 1076, se originaría una reacción local de escribir en un dialecto propio, el riojano, distinto del que se hablaba en Castilla.Y abundando en esta misma cuestión, Hernández Alonso apunta asimismo la conjetura de que los monjes copistas, que conocían "el trasiego de manuscritos de unos monasterios a otros de la misma Orden, al copiar manuscritos de Silos, muy probablemente, anotaran en riojano lo que pudiesen para dejar su 'huella' en ellos, a fin de que pudiera verse en los monasterios castellanos" (pág. 74).

Por último, a juicio de Hernández Alonso, parece innegable aceptar el hecho de que las auténticas glosas, las glosas al "estilo europeo" (pág. 73), son las de Silos $y$, en menor medida, las Emilianenses, que quedarian relegadas a mero instrumento para la enseñanza de la lengua latina: "si por glosas entendemos la serie de anotaciones y acotaciones aclaradoras y explicativas de algunas palabras o frases por medio de otras equivalentes latinas o romances, parece evidente que las auténticas y puras glosas, en objetivos y resultados, son las Silenses; mientras que [...] las Emilianenses muestran un vastísimo número de notas gramaticales acompañadas de unas pocas de carácter léxico y comentarios marginales, mayoritariamente en latín, como instrumento para enseñar latín sobre textos de carácter religioso. No creemos que estas tuvieran la intención de facilitar la comprensión de los textos a los futuros monjes lectores. Las glosas, léxicas, del manuscrito Emilianense son en realidad subsidiarias de las notas gramaticales, para ayudar a explicar el contenido de los textos. No creemos que el monje maestro de latinidad pretendiera seguir una moda europea ni nada semejante" (págs. 72 y 73 ). 
Claro que, frente a estos asertos, hay que hacer notar que los estudiosos del códice Silense, entre los que figura destacadamente Ruiz Asencio, encuentran en ese manuscrito no pocas explicaciones o comentarios escolares. Bien es verdad que, como observa Díaz y Díaz, "a esta explicación escolar parece oponerse radicalmente el uso, demasiado frecuente, de formas verbales de subjuntivo, con toda la carga que el empleo de estas formas suele conllevar"19.

\section{ACOTACIONES CRÍticas}

Uno de los asuntos defendidos con mayor énfasis y reiteración por Ruiz Asencio es la localización en Euskalerría del lugar de escritura de las glosas Emilianenses y el original de la copia actual de las Silenses. A este respecto, creemos conveniente hacer alguna aclaración. La zona de habla vasca, denominada por ese autor "solar de Euskalerría" (pág. 94), abarcaba en los siglos X y XI, además de las Provincias Vascas y Álava, el área occidental de La Rioja (perteneciente ésta al reino de Pamplona hasta el año 1076 y, desde entonces, a Castilla), esto es, el valle de Ojacastro y la zona alta de la propia Rioja.

Si precisamos este aspecto, que Ruiz Asencio desde luego no desconoce, es porque se detecta en el estudio de este profesor una insuficiente valoración del uso de la lengua vasca en esa región de La Rioja ${ }^{20}$, siendo así que, como es bien sabido, a partir sobre todo de mediados del siglo $X$ se cumple allí un asentamiento de población vasca que conlleva, entre otras manifestaciones, la expansión y proliferación del elemento lingüístico vascuence. A este respecto, Menéndez Pidal traza en este territorio las fronteras de la lengua vasca, que abarcan desde la cuenca occidental del Omecillo hasta la desembocadura del Najerilla, con salientes hacia el este, en torno a Nájera, que queda fuera, y en el curso alto del Iregua ${ }^{21}$. En otras palabras, como sintetiza M. Alvar,"por los siglos IX y X, el río Najerilla fue el límite del vascuence ${ }^{22}$.

Por su alcance y trascendencia social y cultural, interesa además resaltar sobremanera que, por una parte, Ruiz Asencio da como muy probable que la

19. DÍAZY DÍAZ, 1978: 36.

20. "Más difícil es determinar en qué zona del Pás Vasco, tal como era en la alta Edad Media, puede estar la patria chica de nuestro hombre. Por razones de tipo geográfico e histórico parece que debemos inclinarnos hacia Álava, donde tantos intereses tuvo el monasterio de San Millán, como todas las otras instituciones eclesiásticas importantes asentadas en la zona sur de La Rioja. Tal vez incluso pueda proceder del riojano Valle de Ojacastro, antaño perteneciente a Castilla y hoy en La Rioja, donde, como es bien sabido, el vascuence estuvo en uso hasta la baja Edad Media. Puede ser que los rasgos de navarrismo que algún sabio investigador ha notado en las glosas romances sean válidos para todos los habitantes de Euskalerría cuando se ven obligados a expresarse según el modo romance; quiero decir que quizá en el siglo XI los de Álava tuvieran idénticas soluciones fonéticas y sintácticas que los de la Navarra vasca" (pág. 107).

21. Cfr. MENÉNDEZ PIDAL, 1986:465, el mapa titulado "El último reducto de los dialectos ibéricos".

22. ALVAR, 1976: 
copia del códice Silense se escribió en San Millán de la Cogolla y, por otra, que Hernández Alonso, a su vez, no duda en afirmar que el texto de las Silenses está escrito en el dialecto de La Rioja. En otros términos, ambos autores plantean de tal modo sus argumentos históricos y lingüísticos que, a partir de ahora, va a resultar todavía más difícil concluir que las glosas Silenses, así como las Emilianenses, no se escribieran en La Rioja.

En el apartado de la datación de estos venerables textos, merced, sobre todo, a una metodología paleográfica cada vez más rigurosa, se han logrado por los científicos reseñados precisiones significativas. Son estas: el texto de base de las glosas Emilianenses se copiaría en la segunda mitad del siglo XI, es decir, aproximadamente un siglo y medio después de la fecha comúnmente establecida ${ }^{23}$. Por otra parte, las glosas Emilianenses se escribirían en el último cuarto del siglo XI y la copia actual de las Silenses en fecha inmediatamente posterior (de finales del XI a principios del XII). Adviértase que en ambos casos la datación se retrasa algunas décadas en relación con la cronología pretendida por especialistas del relieve de Díaz y Díaz ${ }^{24}$.

Bien es verdad que, a nuestro juicio, ni los argumentos de orden paleográfico ni las razones de carácter lingüístico aducidos (por no mencionar la inoperancia ya tradicional del enfoque estrictamente histórico) resultan claramente convincentes.

Los primeros se nos muestran sin demasiada consistencia. En primer lugar, hay tres ejemplos en total de un $u$ el carolino. A este respecto, hacemos notar, entre otros testimonios, un caso de abreviatura $l$ con travesaño para el valor de uel en una pizarra del año 642-649, que procede seguramente del Tiemblo ${ }^{25}$. Otro ejemplo, de análogas características, se recoge en el glosario emilianense (Real Academia de la Historia, cod. 46), del año 964, en ortum: generatum uel natum. Sin embargo, el manuscrito silense Biblioteca Nacional de París, N.a.l. 1296, copiado, sin lugar a dudas, del cód. 46, y escrito, para Díaz y Díaz, "muy a finales del siglo $\mathrm{X}$, o mejor aún a comienzos del siglo XI"26, abrevia el uel como $u l$, al modo tradicional.

En segundo lugar, se consigna un único testimonio, y dudoso, de $u s$ a la francesa. Dudoso por varios motivos. Por su colocación, ya que la panza del 9 cursivo -en realidad, una $o$ - se apoya directamente sobre el renglón, frente a la posición volada que adopta en el sistema gráfico carolino ${ }^{27}$; y además, el caído del 9 resulta, según nuestra apreciación, ajeno al signo mencionado, y ejecutado en

23. Cfr. nuestra n. 11 .

24. Cfr. nuestra n. 13.

25. Cfr. VELÁZQUEZ SORLANO, 1989: núms. 92, 132 y 291.

26. DÍAZY DÍAZ, 1978, 13. Por su parte, VTVANCOS GÓMEZ, 1996: 71, lo lleva, sin dudarlo, a finales del siglo XI.

27. A este respecto, MILLARES CARLO, 1983: 113, afirma:"colócase este signo en la parte superior derecha de la letra básica de la sílaba abreviada, ya final de palabra, ya, a veces, intermedia" 
un segundo momento. Por su trazado fino y rápido, que se asemeja más a los numerosos "trazos supérfluos" y a otros signos de llamada, abundantes en los espacios interlineales del texto de base, que a los pies de las letras (como $q$ o $\not D$, por ejemplo), gruesos y pesados. Es más, el propio Ruiz Asencio advierte, con razón, que "el sentido [de la frase] pide templo" (pág. 92) ${ }^{28}$.

Finalmente, en este apartado paleográfico conviene introducir algunas precisiones. Por una parte, nos parece evidente que la grafía de la abreviatura de per con línea cortando el caído de $p$ es rigurosamente autóctona: su presencia en numerosas pizarras visigodas así lo confirma ${ }^{29}$. Asimismo, es preciso aclarar que el alógrafo visigótico más común ( $p$ que lleva en su pie un signo irregular situado a la izquierda) funciona como abreviatura no sólo de per sino también -aunque en menor medida- de prae, pre y pro, como se comprueba en varios manuscritos riojanos de la segunda mitad del siglo X. He aquí algunos ejemplos: grassatur: praedat; alites: [...] prepetes; exidisse: produisse, etc. (Real Academia de la Historia, cod. 46); Scio aliquantos post baec deinceps promoberi posse (Ibíd, cód. 78, fol. 72v), etc. Por otra, la abreviatura de in considerada carolina (cfr. nuestra nota núm. 29), consistente en una $l$ alta con línea que cruza el astil, se encuentra ya en una pízarra de Ávila del siglo VII $^{30}$. Por último, será útil dar a conocer algunos aspectos relacionados con la forma del crismón, que aparece en el texto de base del Amilianensis 60 (fol.66v, línea 8). Aunque coincidimos con la opinión del profesor Ruiz Asencio, cuando afirma que durante el siglo X "los documentos visigóticos tienen casi siempre el crismón con forma de báculo y en él un signo de clave de sol" (pág. 92), nos interesa hacer ver que, ya en esa misma centuria, dos códices que transmiten las Etymologias de San Isidoro (uno, de Cardeña, año 954? ${ }^{31}$; otro, de San Millán de la Cogolla, año 94632), en el epígrafe titulado De notis sententiarum (Liber I), recogen un modelo de Crismon, en

28. Llevado quizá por esta interpretación, el citado investigador transcribe el término en cuestión como templo y no como templus (pág. 220), lectura que también recogen GARCÍA LARRAGUETA, 1984; 157, y WOLF, 1991: 150.

29. Cfr. VELÁZQUEZ SORIANO, 1989, núms. 5, 31, 42, etc. Ya se refieren a la antigüedad de esta forma algunos de los maestros de la paleografía. Seleccionamos la siguiente opinión de MULLARES CARLO, 1983, 90: "Quizá esté en lo cierto Clark al suponer que la primera forma [ $p$ con línea cortando el caído] sea la más antigua ("nota iuris") y origen de las restantes, que son características de la escritura visigótica”. Con mayor firmeza, Ruiz Asencio separa esta abreviatura (así como la del empleo de la $I$ alta con travesaño para abreviar $i n$, y de $d$ y $k$ con la línea cruzando el astil para abreviar de y ke) de las formas consideradas mayoritariamente como claros influjos carolinos; éstas, a su juicio, "son soluciones gráficas que encontramos en documentos y en algunos códices visigóticos anteriores a la existencia del influjo ultrapirenaico en los reinos peninsulares" (pág. 99). En la misma línea, no estaría demás advertir aquí que la atribución de características formales carolingias al segundo elemento del nexo st debería replantearse a la vista de los múltiples testimonios que se encuentran en manuscritos de la décima centuria (Real Academia de la Historia, códs. 25, 46, 76, etc.) y, lo que es aún más destacable, en varias pizarras hispánicas de los siglos VII y VIII.

30. Cfr. VELÁZQUEZ SORIANO, 1989: 240 y 241, núm. 54.

31. Real Academia de la Historia, cód. 76.

32. Ibíd, cód. 25. 
ambos manuscritos idéntico, que es el resultado de superponer una $X$ a una $P$, y que se define como "baec sola ex uolumtate uniuscuiusque ad aliquid notantum ponitur (fols. $4 \mathrm{v}$ y $17 \mathrm{v}$, respectivamente).

En cuanto a las razones lingüísticas aducidas por Hernández Alonso (inexistencia de -airo o -eiro, monoptongación única de $\mathrm{AU}>0$ y cambio de timbre de la vocal postónica conservada), parece necesario aclarar algunas cuestiones.

En primer lugar, con relación a los descendientes de -ARIU, Menéndez Pidal reconoce que para Castilla no dispone de suficientes ejemplos como para intentar un análisis estadístico, aunque, eso sí, los pocos casos documentados le permiten comprobar que en esa región vivía aún el diptongo,"si bien olvidado ya de su grado primitivo -air, y relegado a regiones apartadas de Burgos" ${ }^{33}$. En concreto, recoge 18 testimonios burgaleses de la segunda mitad del siglo X (procedentes de Ibeas de Juarros, Covarrubias, Cardeña, etc.), entre los que no aparece ningún -airo y ni siquiera un -eiro, siendo -ero el resultado único.

Por otra parte, para el reino navarro-aragonés, Menéndez Pidal declara la imposibilidad de un análisis adecuado ya que de la décima centuria no tiene más ejemplo que el terzero de las Glosas Emilianenses $9^{34}$.

En rigor, la conclusión a que llega Hernández Alonso ("De ningún modo podemos retrotraerlas [las Glosas, Emilianenses y Silenses] al siglo X, en que un 35\% de los casos estudiados utilizan -airo, -eiro, y un 65\% -ero", pág. 76) tendría validez únicamente si las Glosas se hubieran escrito en alguno de los subdialectos leoneses. En efecto, los porcentajes que presenta este investigador se corresponden exactamente con los extraídos por Menéndez Pidal de documentos de la ciudad de León y del Monasterio de Sahagún, escritos en la segunda mitad del siglo $\mathrm{X}^{35}$.

En segundo lugar, respecto de la monoptongación o (<au secundario, derivado de $\mathrm{AL}+\mathrm{T}$ ), la razón en que se basa Hernández Alonso para demostrar que los casos sotare (GISil 251) y su postverbal sota (GISil 258) presentan una evolución tardía (textualmente: "pues la forma soto y otba, según Menéndez Pidal, no aparece casi hasta el siglo XII", pág. 77), a nuestro juicio, sólo podría aceptarse si en La Rioja y regiones periféricas se documentaran suficientemente, durante la décima centuria, resultados de SALTARE y de ALTU con diptongo. Pero al analizar minuciosamente este problema en los Orígenes, se comprueba que Menéndez Pidal tan solo encuentra en escrituras de ese siglo las formas sautieIlo (año 978, Covarrubias; hay un Sotiello, en Oña, de 1063) y Villa auta (año 973, Cardeña; pero Riba otha, Burgos, año 1107), al lado, claro está, de los dos ejemplos de las Glosas Silenses, que, como es bien sabido, él las consideró escri-

33. MENÉNDEZ PIDAL, 1986: 74.

34. Ibíd.

35. Ibíd:: 71 . 
tas en el siglo X. En otras palabras, a lo largo de este siglo, y en Castilla, La Rioja, Navarra y Aragón, no se hallan testimonios monoptongados de descendientes de SALTARE o ALTUS, pero no por exigencias propias de la evolución del sistema fonológico, sino simplemente por escasez de datos.

Finalmente, la conservación de la vocal postónica no etimológica de cuempetet (GIEmil 68 <COMPUTET 'cuente'), otro de los datos fonéticos que apoyan la creencia de Hernández Alonso "de que las Glosas pertenecen a la segunda mitad del siglo XI, y son anteriores al 1080 [?]" (pág. 78), precisa, asimismo, alguna matización. Importa, antes de nada, destacar que el fenómeno en cuestión, que, según Hernández Alonso, "R. Menéndez Pidal (Orígenes, p. 512) sitúa entre 1067 y 1100" (Ibíd.), se atestigua ya desde el siglo X. En efecto, de los cuatro ejemplos estudiados por Menéndez Pidal (competent 1059 Aragón, riuilo 972 Covarrubias <RIVUULU, Esidero 1098 Sahg <ISIDORUS, inmouole 990 Sahg $<$ INMOBILE) ${ }^{36}$, dos, como puede observarse, pertenecen a esa centuria. Pero conviene, asimismo, puntualizar que los testimonios de este fenómeno, que se usa todavía mucho en todas partes durante el período de lucha por la hegemonía castellana (de 1067 a 1140; y no de 1067 a 1100, cfr. supra), son considerados por Menéndez Pidal ${ }^{37}$ arcaísmos, emparentados con los más frecuentes de vocal postónica (o protónica) etimológica conservada.

Todas estas precisiones nuestras quieren alertar sobre la tendencia, hoy bastante generalizada, a exagerar el retraso de la datación de las Glosas, especialmente si no se pierde de vista, como muy bien señala el mismo Ruiz Asencio, que "Uno de los desafios cientíticos, aún pendiente, que tienen los paleógrafos españoles es el establecimiento de unos criterios científicos fiables para datar la masa conservada de manuscritos visigóticos" (pág. 90) ${ }^{38}$.

Por otra parte, no nos parece, desde luego, adecuada la denominación de "castellano-riojano" que utiliza Hernández Alonso para referirse a la lengua en que se escriben las glosas Emilianenses y Silenses. A nuestro juicio, éstas son la primera manifestación escrita del dialecto riojano; en rigor, del habla altorriojana, una modalidad del romance español medieval. En efecto, conviene precisar con Emilio Alarcos, que en ellas son más las singularidades distantes del castellano y comunes con las de los otros dialectos o romances vecinos (aragonés, navarro, leonés y mozárabe), que los rasgos análogos a los que se estabilizaron en el castellano literario medieval con la normalización elaborada por Alfonso X el Sabio.

36. Ibíd: 165 .

37. Ibíd: 165-166 y $511-512$

38. En el mismo sentido vienen manifestándose todos los especialistas en la escritura visigótica. Así, recientemente, ALTURO, 1994: 33 se lamenta: "este capítulo [el de la escritura denominada visigótica], aun aportando ya una notable bibliografia, no ilustra suficientemente nuestros conocimientos sobre no pocos aspectos y detalles del mayor interés, todavía en la penumbra. Sin ir más lejos está pendiente de resolución definitiva determinar el origen geográfico de esta modalidad de escritura, si ya no su mismo origen genético". 
En otras palabras de este mismo profesor,"La lengua que reflejan estas glosas, de acuerdo con la localización geográfica en que se escribieron, es en realidad una muestra, defectuosamente manifestada por la grafia, del romance que se hablaría entonces en la región, es decir, en esta Rioja, zona de interferencia de pueblos y lenguas desde los tiempos prerromanos" ${ }^{39}$. Asimismo, habrá que recordar que, en términos muy parecidos, ya se manifestó Menéndez Pidal: "En estas Glosas Emilianenses vemos el habla riojana del siglo X muy impregnada de los caracteres navarro-aragoneses" ${ }^{\prime 40}$. Nos interesa insistir en el hecho de que el riojano es un dialecto cuya singularidad radica precisamente en la convivencia de una gran variedad de componentes (castellanos, navarros, aragoneses, vascos y los específicamente riojanos). Así ha caracterizado la singularidad lingüística de La Rioja Manuel Alvar: "La personalidad de las Riojas Alta y Baja, reside, precisamente, en la pluralidad de normas lingüísticas. Y personalidad es también el mantenimiento de esas normas múltiples con las que unas gentes han creado sus vehículos expresivos. Aquí está, a mi modo de ver, la realidad del dialecto riojano como existencia singular: dialecto ecléctico en cuanto a la variedad de sus componentes, pero inexistente si desligamos la fusión" ${ }^{\prime \prime 1}$. 


\section{BIBLIOGRAFÍA}

ALARCOS LLORACH, E.

El español, lengua milenaria (y otros escritos castellanos). Valladolid, 1982.

ALTURO, J.

"La escritura visigótica de origen transpirenaico. Una aproximación a sus particularidades", Hispania Sacra, 46 (1994), págs. 33-64.

ALVAR, M.

El dialecto riojano. Madrid, 1976.

DÍAZ Y DÍAZ, M. C.

Las primeras glosas hispánicas. Barcelona, 1978.

DÍAZ Y DÍAZ, M. C.

Libros y Librerías en La Rioja Alto Medieval. Logroño, 1991².

GARCÍA LARRAGUETA, $S$.

Las glosas emilianenses. Edición y estudio. Logroño, 1984.

HERNÁNDEZ ALONSO, C., et alii.

Las Glosas Emilianenses y Silenses. Edición crítica y facsímil. Burgos, 1993.

MENÉNDEZ PIDAL, R.

Orígenes del Español. Estado lingüístico de la Península Ibérica hasta el siglo XI. Madrid, $1986^{10}$.

MILLARES CARLO, A.

Tratado de Paleografía Española. Con la colaboración de J. M. Ruiz Asencio. Madrid, 1983.

VELÁZQUEZ SORLANO, I.

Las pizarras visigodas: edición crítica y estudio. Murcia, 1989.

VIVANCOS GÓMEZ, M. C.

Glosas y notas marginales de los manuscritos visigóticos del Monasterio de Santo Domingo de Silos. Silos, 1996.

WOLF, H.J.

Glosas Emilianenses. Hamburg, 1991. 